\title{
DA TEXTURA ABERTA DA LINGUAGEM À TEXTURA ABERTA DO DIREITO: O CONTRIBUTO DE WITTGENSTEIN E WAISMANN À FILOSOFIA JURÍDICA DE
}

HART

FROM THE OPEN TEXTURE OF LANGUAGE TO THE OPEN TEXTURE OF THE LAW: THE CONTRIBUTION OF WITTGENSTEIN AND WAISMANN TO THE LEGAL PHILOSOPHY OF HART

Charles Nunes Bahia ${ }^{1}$

ISSUE DOI: $10.21207 / 1983.4225 .333$

\section{RESUMO}

Hart trouxe ao campo jurídico a constatação de que o Direito possui uma textura aberta. Toda essa abertura parecia ser uma consequência das imprecisões da linguagem. Um retorno a Wittgenstein e Waismann mostravase medida necessária para entender a vagueza normativa como uma consequência direta do fenômeno linguístico. Destarte, será sobre a relação simbiótica estabelecida entre as teorias desses três autores que se fundará o presente artigo.

Palavras-chave: Jogos de linguagem. Textura aberta da linguagem. Textura aberta do direito. Discricionariedade judicial.

\footnotetext{
${ }^{1}$ Advogado. Bacharel em Direito pela PUC Minas (2012). Realizou graduação sanduíche na Universidade do Porto (Portugal) - 2011/2012. Mestre em Teoria do Direito pela PUC Minas (2016). Graduando em Filosofia pela UFMG.
} 


\section{ABSTRACT}

Hart brought to the legal field the finding that the law has an open texture. All this opening appeared to be a consequence of the imprecision of language. A return to Wittgenstein and Waismann showed up as necessary to understand the normative vagueness as a direct consequence of the linguistic phenomenon. Thus, it will be on the symbiotic relationship established between the theories of these three authors that will find this Article.

Keywords: Language games. Open texture of language. Open texture of law. Judicial discretion.

\section{INTRODUÇÃO}

A incerteza trazida pelo Direito é uma esfinge que se apresenta transvestida das mais diversas interrogações. A dificuldade do legislador em legislar sobre eventos futuros, assim como a frustração do magistrado ao se deparar com as mais diversas lacunas normativas são apenas marcas constitutivas de um espaço formalmente denominado universo jurídico. Mas afinal, quais são as razões para que a ausência de previsibilidade se debruce sobre normas jurídicas e acabe por frustrar as expectativas dos jurisdicionados? Ao que parece, o inglês Herbert Hart tinha a resposta para alegórico dilema. Era necessário reconhecer que o Direito possui uma textura aberta.

Para o positivismo jurídico analítico de Hart, a textura aberta do Direito apresenta-se como resultado claro da imprecisão linguística na qual se funda a construção das normas jurídicas. A normatividade que garante um pouco de certeza à esfera jurídica é a mesma que se desintegra diante dos engodos da linguagem. Uma zona de penumbra normativa se faz inerente; deve ser ela consequência de uma textura aberta da linguagem.

Há, então, uma relação direta entre a textura aberta da linguagem e a textura aberta do Direito. Essa relação jurídico-filosófica, no entanto, é, antes de tudo, absolutamente filosófica, uma vez que encontra em Waismann um singular expoente. Deve-se ter em conta que foi esse filósofo austríaco o responsável por afirmar que a linguagem possui uma indiscutível textura aberta, fruto da potencial vagueza de conceitos empíricos.

A textura aberta da linguagem, por sua vez, remete a outros meandros filosóficos. Conforme se verá, suas origens podem ser facilmente 
encontradas e assimiladas às ideias de jogos de linguagem e hipótese, ideias estas fundadas em matrizes puramente wittgensteinianas. É, pois, Wittgenstein o responsável por inaugurar conceitos que mais tarde adentrariam a esfera jurídica. Por este motivo, iniciar-se-ão as desenvolturas deste trabalho tomando-se como carro-chefe as considerações teóricas semeadas por esse filósofo da Áustria.

\section{WITTGENSTEIN E A IDEIA DE JOGOS DE LINGUAGEM}

O que são jogos de linguagem? O que de fato a metafórica expressão quer dizer? Responder a essas perguntas exige um retorno ao segundo Wittgenstein. A possiblidade de delimitar duas fases da teoria wittgensteiniana traz consigo uma ideia de ruptura e não de transformação da visão adotada por esse filósofo austríaco. ${ }^{2}$ Se na obra Tractatus a linguagem encontra sua essência na figuração do mundo, na obra Investigações Filosóficas essa essência é perdida, dando origem à ideia de jogos de linguagem.

No Tractatus, o que está disposto na linguagem é o que está convencionado no mundo. Logo, a estrutura da linguagem deve ser igual à estrutura do mundo. Nesse sentido, se por algum equívoco ou mero deslize, a linguagem deixar de capturar sua essência (o mundo), surgirá um contrassenso. Este, oriundo de questões metafísicas, se mostrará imensamente prejudicial à filosofia. Questões metafísicas, por não capturarem a essência da linguagem, não podem ser objeto de indagações filosóficas; são elas pseudoquestões e, justamente por carregarem consigo esse título de falseabilidade é que sobre elas não se pode falar, devendo se calar; habitam, pois, o campo do indizível. ${ }^{3}$ Sem embargos, é possível afirmar que a intenção de Wittgenstein era apartar dos limites da filosofia tudo aquilo que ultrapassasse as barreiras da linguagem. Feito isso, tudo o que sobrasse submergiria ao campo místico, considerado por ele o espaço de condução da vida humana tanto em termos éticos quanto estéticos.

2 CAVASSANE, Ricardo Peraça. A crítica de Wittgenstein ao seu Tractatus nas Investigações Filosóficas. In: Revista de Iniciação Científica da F.F.C., v 10, p. 3, 2010.

${ }^{3}$ WITTGENSTEIN, Ludwig. Tratado lógico-filosófico. Tradução de M. S. Lourenço. Lisboa: Fundação Calouste Gulbenkian, 2002b. 
O fato é que o próprio Wittgenstein acabou se convencendo de que a função da linguagem não era apenas capturar o mundo; teria ela vários outros papéis. Diante dessa nova forma de se pensar, a ideia de essência caía por terra e, a partir daí, renegada estaria a um profundo ostracismo. Para suprir a lacuna e rearranjar o espaço deixado pela ruptura com o Tractatus, o filósofo austríaco opta por trazer ao centro das Investigações Filosóficas um novo conceito: jogos de linguagem.

A partir dessa conceituação demarcatória da segunda fase wittgensteiniana é que se desenvolve o presente tópico. Aqui a linguagem se torna uma atividade; ela deixa de figurar como essência do mundo para ser utilizada como mecanismo necessário à realização das mais diferentes funções. Os termos que a compõem se abrem às mais diversas possibilidades interpretativas. Assim, por exemplo, se uma criança pergunta ao pai advogado o que seja determinado livro, apontando para o objeto que se apresenta na forma de incógnita, o pai responderá ser o Código Penal. Entretanto, se esse mesmo advogado diz ao seu estagiário "Código Penal", o que ele quer dizer é que esse estagiário lhe passe ou lhe consiga um Código Penal. Essa diferença contextual aqui exemplificada é definida por Wittgenstein por meio da noção de jogos de linguagem, expressão que realça para o filósofo austríaco o fato de que "falar uma língua é uma parte de uma atividade ou uma forma de vida". ${ }^{4}$ Nesse sentido, a utilização da linguagem como ferramenta pode ser explicada através da seguinte indagação wittgensteiniana:

Mas quantas espécies de proposições há? Talvez asserção, pergunta e ordem? Há um número incontável de espécies: incontáveis espécies diferentes da aplicação daquilo a que chamamos símbolos, palavras, proposições. E esta multiplicidade não é nada de fixo, dado de uma vez por todas; mas antes novos tipos de linguagem, novos jogos, como poderíamos dizer, surgem e outros envelhecem e são esquecidos. ${ }^{5}$

${ }^{4}$ WITTGENSTEIN, Ludwig. Investigações filosóficas. Tradução de M. S. Lourenço. Lisboa: Fundação Calouste Gulbenkian, 2002a. p. 189.

${ }^{5}$ Ibidem. 
O que Wittgenstein quer dizer resume-se no seguinte raciocínio: existe um incontável número de proposições na linguagem que se combinam através de jogos. Da mesma maneira como ocorre em relação aos jogos, também em relação à linguagem não é possível encontrar uma característica unívoca capaz de ser identificada em todas as instâncias linguísticas; existem apenas semelhanças relevantes que agrupam essas expressões em determinados espaços da compreensão durante um lapso temporal. Grosso modo, a compreensão desse raciocínio pode assim ser descrita:

Considera, por exemplo, os processos aos quais chamamos jogos. Quero com isto dizer os jogos de tabuleiro, os jogos de carta, os jogos de bola, os jogos de combate, etc. O que é comum a todos eles? Não respondas: tem de haver alguma coisa em comum, senão não se chamariam jogos - mas olha, para ver se tem alguma coisa em comum. - Porque, quando olhares para eles não verás de fato o que todos têm em comum, mas verás parecenças, parentescos, e em grande quantidade. ${ }^{6}$

A passagem acima transcrita deixa clara a ideia de que os jogos compartilham o tempo todo semelhanças que aparecem e desaparecem. Determinadas características são semelhantes para alguns jogos e diferentes para outros. Essa contingência de traços e peculiaridades se daria, para Wittgenstein, da forma como se dão as semelhanças de família, "porque as diversas parecenças entre os membros de uma família, constituição, traços faciais, cor dos olhos, andar, temperamento, etc., etc., sobrepõem-se e cruzam-se da mesma maneira". ${ }^{7}$ Para ele, os jogos constituem uma família.

A noção de semelhanças de família adentra ao campo teórico de modo singular, alcançando uma possível teoria da linguagem. Da mesma forma como não existe uma essência a ser compartilhada pelos jogos, também não existe aludida essência em relação à linguagem. $\mathrm{O}$ que existe na linguagem são semelhanças de família condicionadas às mudanças que se impõem no transcorrer da barca que tange o tempo. Essas mudanças, todavia, trazem consigo determinadas consequências; elas provam que os jogos

${ }^{6}$ WITTGENSTEIN, Ludwig. Investigações filosóficas. Tradução de M. S. Lourenço. Lisboa: Fundação Calouste Gulbenkian, 2002a. p. 227.

${ }^{7}$ Ibidem. p. 228-229. 
não conseguem ser totalmente submetidos a regras. Assim, por exemplo, "não há uma regra que determine no tênis a que altura se deve jogar a bola, ou com que força e, no entanto, o tênis é um jogo e também tem regras".

Essa margem de abertura que possibilita aos jogos que se encontrem livres de determinadas regras, apresenta-se como a representação mais fidedigna de um espaço vazio que torna translúcida uma representação exata desses jogos. Na linguagem ocorre justamente a mesma coisa, haja vista o fato de que a ausência de regras suficientes aos usos da língua, faz gerar casos fronteiriços, ou seja, casos nos quais persiste inafastável dúvida sobre a utilização ou não de determinado conceito. Como se verá mais à frente, será essa região cinzenta, na qual nada parece ser estabelecido por meio da certeza, a responsável por realizar a passagem da filosofia pura à filosofia jurídica analítica. ${ }^{9}$

\section{WAISMANN E A NOÇÃO DE TEXTURA ABERTA DA LINGUAGEM}

Foram vários os encontros entre Wittgenstein e Waismann. Os assuntos tratados em várias ocasiões, ao que parece, estavam voltados àquelas questões fundamentais ao correto desenvolvimento de uma filosofia da linguagem. Não é segredo algum que a noção de textura aberta da linguagem, cunhada por Waismann enquanto membro do Círculo de Viena, permanece indubitavelmente arraigada a conceitos wittgensteinianos. No entanto, antes de se buscar os elementos percussores desse modelo fundado no positivismo lógico, faz-se necessário definir o que seja essa zona cinzenta ocupada pela linguagem.

A filosofia da linguagem assumia posição protagonista no início de século XX marcado pela influência do Círculo de Viena. Bases empíricas eram novamente contextualizadas enquanto o conhecimento científico tornava-se o objeto e o rigor do estudo. Significados digladiavam-se em meio às aspirações e certezas trazidas pela cientificidade. Não é à toa que a famosa afirmação de Waismann de que "o significado de uma afirmação

\footnotetext{
8 WITTGENSTEIN, Ludwig. Investigações filosóficas. Tradução de M. S. Lourenço. Lisboa: Fundação Calouste Gulbenkian, 2002a. p. 230.

${ }^{9}$ STRUCHINER, Noel. Uma análise da textura aberta da linguagem e sua aplicação ao direito. Dissertação (Mestrado em Filosofia) - Pontifícia Universidade Católica do Rio de Janeiro (PUC-RJ), Rio de Janeiro, 2001. p. 20.
} 
aduz o seu método de verificação"10, ganha tamanha importância; estava ela imersa nas divagações trazidas pelos positivistas lógicos. Waismann, ao trazer para o centro de sua teoria as ideias de significado e verificação, o faz seguindo os passos de seu mestre, Moritz Schlick. Agregava ele ao seu viés teórico, portanto, a visão schlickiana segundo a qual "o significado de uma afirmação é fornecido pelo método de verificação, que consiste em fornecer as condições que devem ser obtidas para que ela seja verdadeira". ${ }^{11}$

Para Waismann, o método de verificação deve-se submeter a determinadas condições necessárias, capazes de atribuir-lhe veracidade. $\mathrm{O}$ fato é que esse método verificacionista muitas vezes se confunde diante das ilusões da linguagem; isso significa dizer que determinadas palavras podem se combinar de uma forma tal que sejam geradas significações inéditas, sendo esse ineditismo comprometedor ao significado da expressão. ${ }^{12}$ Assim, expressões como "a planta está naquele lugar onde ela recebe a luz do sol" não causa estranheza, tampouco confusões em relação à sua significação. Por outro lado, expressões como "a planta sentiu a mudança de lugar, pois agora não mais recebe a luz do sol", já causa estranheza. Neste último caso, o verbo sentir soa estranho, pois remete à possibilidade de que o vegetal possua sensibilidade nevrálgica ou mesmo sentimento. Esta afirmação, por óbvio, comprometeria o significado da expressão se não fosse possível estabelecer condições de verdade, ou seja, um método de verificação capaz de esclarecer como essa noção de sentimento possa ter significação em relação a uma planta. Aqui a verificação atua, portanto, como significado.

A explicação desse exemplo que se acabou de fazer alusão pode ser muito simples se se partir do pressuposto de que exista um método de verificação para ele. Com clareza, seria possível afirmar que a planta na verdade não sentiu a mudança de lugar; que a frase problemática apenas fez uso da personificação como figura de linguagem de modo a dar ânimo a um ser inanimado. Destarte, a sensibilidade a qual ora se faz alusão não

\footnotetext{
${ }^{10}$ WAISMANN, Friedrich. Verifiability. In: FLEW, Antony (coord.). Logic and language. Oxford: Balckwell, 1978. p. 117.

${ }^{11}$ STRUCHINER, Noel. Uma análise da textura aberta da linguagem e sua aplicação ao direito. Dissertação (Mestrado em Filosofia) - Pontifícia Universidade Católica do Rio de Janeiro (PUC-RJ), Rio de Janeiro, 2001. p. 9.

${ }^{12}$ WAISMANN, Friedrich. Verifiability. In: FLEW, Antony (coord.). Logic and language. Oxford: Balckwell, 1978, p. 177-144.
} 
passa de uma reação do vegetal à ausência de luz e, por conseguinte, à dificuldade na realização da fotossíntese.

Deve-se ter em conta que embora o método de verificação seja o passaporte à tão almejada significação, ele dificilmente consegue esgotar o significado $^{13}$, isso porque nem sempre a verificação implica uma afirmação. Ao que se sabe, a verificação contribui para a afirmação, já que serve como evidência àquilo que se afirma. A afirmação se mostra, pois, uma decorrência de diversas verificações, mas com essas não pode ser confundida.

Não se deve olvidar, ainda, que existem casos nos quais determinadas verificações não conseguem conduzir a uma afirmação. Tal impossibilidade, ao que tudo indica, é uma decorrência da textura aberta da linguagem, explicada por Struchiner da seguinte forma:

Por textura aberta da linguagem, Waismann pretende dizer que os nossos conceitos empíricos não estão delimitados, de forma a priori, em todas as direções possíveis. Os conceitos empíricos não apresentam uma definição exaustiva, ou seja, nenhum conceito se encontra delimitado de forma que não surjam espaços para dúvida sobre o seu significado. ${ }^{14}$

A imensidão de conceitos existentes na linguagem é que faz gerar essa textura aberta. São várias as possibilidades de aplicação de determinada expressão; a todo tempo surgem novas possiblidades antes não conhecidas. Assim, por exemplo, poder-se-ia perguntar se um Marciano que possua as mesmas características físicas e intelectuais que possui um ser humano poderia ser considerado um ser humano como tal. Ao realizar este questionamento, torna-se fácil perceber que o termo ser humano seja possuidor de uma textura aberta. Com isso, a crença de que o termo esteja bem definido na sociedade, englobando todos aqueles seres racionais, pode ser facilmente desmantelada pela possibilidade de que outros seres racionais

\footnotetext{
${ }^{13}$ WAISMANN, Friedrich. Verifiability. In: FLEW, Antony (coord.). Logic and language. Oxford: Balckwell, 1978, p. 119.

${ }^{14}$ STRUCHINER, Noel. Uma análise da textura aberta da linguagem e sua aplicação ao direito. Dissertação (Mestrado em Filosofia) - Pontifícia Universidade Católica do Rio de Janeiro (PUC-RJ), Rio de Janeiro, 2001. p. 11.
} 
apareçam. Permanece, portanto, uma zona cinzenta deixada em aberto, zona esta não passível de definição em decorrência da vagueza a qual a linguagem se encontra submetida. ${ }^{15}$

A definição de ser humano, bem como de vários outros conceitos empíricos, não se exaure, já que fica condicionada a uma região lacunosa à espreita de novas significações. Nesse espaço de lacunas, percebe-se uma vagueza extrema da linguagem, incapaz de ser sanada. É justamente aí que se manifesta a textura aberta. ${ }^{16}$

Waismann afirma que a textura aberta da linguagem é uma questão de incompletude essencial. ${ }^{17} \mathrm{Com}$ isso ele quer dizer que por mais que se tente fornecer uma descrição precisa sobre determinado objeto, permanecerão sempre itens faltantes, deixando o objeto descrito sujeito a imprecisões. Logo, se um indivíduo, por exemplo, resolve descrever sua casa como possuindo dois andares, quatro quartos, duas salas, três banheiros, uma cozinha, um porão, etc., tem ele a consciência de que ficarão faltando sempre alguns componentes, que, uma vez omitidos, podem conduzir à incerteza da linguagem, ou seja, a uma textura aberta. Isso se dá porque o objeto casa é empírico e, por isso, a tarefa que sobre ele recai não se esgota na descrição realizada por esse indivíduo.

A textura aberta é, portanto, o resultado lógico da infinidade de combinações possíveis através do uso da linguagem. De modo geral, podese dizer ser ela uma decorrência inevitável dos jogos de linguagem de Wittgenstein e, a partir desta afirmação, torna-se claro o paralelo da teoria de Waismann com o legado wittgensteiniano. A própria ideia de semelhanças de família remete à vagueza dos conceitos linguísticos, o que pode ser percebido através da dinamicidade dos termos que se combinam nos jogos de linguagem. No mais, percebe-se que tanto as expressões submetidas à região da textura aberta, como aquelas submetidas às semelhanças de família, "possuem contornos imprecisos, podendo ter a extensão de sua aplicação alterada no tempo". ${ }^{18}$

\footnotetext{
${ }^{15}$ WAISMANN, Friedrich. Verifiability. In: FLEW, Antony (coord.). Logic and language. Oxford: Balckwell, 1978, p. 119.

${ }^{16}$ Ibidem. p. 122.

17 Ibidem.

${ }^{18}$ STRUCHINER, Noel. Uma análise da textura aberta da linguagem e sua aplicação ao direito. Dissertação (Mestrado em Filosofia) - Pontifícia Universidade Católica do Rio de Janeiro (PUC-RJ), Rio de Janeiro, 2001. p. 20.
} 
Para além da zona de arrebentação na qual se estabelecem os jogos de linguagem, exerce a ideia wittgensteiniana de hipótese um inegável papel de peso na conceituação do que seja a textura aberta da linguagem, isso porque:

Uma hipótese admite múltiplas verificações independentes, mas nenhuma delas, nem nenhuma combinação delas, é conclusiva. No máximo, uma hipótese se torna provável em função das evidências que servem para confirmá-la, mas nunca certa. ${ }^{19}$

Como se pode ver, a hipótese traz consigo a ideia de probabilidade, de incerteza, assim como a ideia de textura aberta. Segundo Guilherme Silva, essa mesma conceituação, atrelada às predileções wittgensteinianas, se dá do seguinte modo:

A hipótese é a regra por meio da qual conectamos diferentes aspectos fenomênicos, dados no constante fluxo presente da experiência imediata, em formas 'inalteráveis e estáveis', que denominamos de objeto físico, passíveis de serem situados no tempo homogêneo fisicalista. Além, disso, o uso das hipóteses também tem em vista fazer predileções. Por essa razão ele [Wittgenstein] afirma que 'uma hipótese é uma lei para formar expectativas. Em resumo, a hipótese é uma regra que permite conectar os dados imediatos em formas que perduram e obter proposições a serem comparadas futuramente com a experiência imediata. ${ }^{20}$

Esse conceito, ao que se percebe, apenas vem reiterar o fato de que seja a incerteza aquela que move o ideal wittgensteiniano de hipótese. São expectativas, desconhecimento e incansáveis verificações que formam

${ }^{19}$ BAKER apud STRUCHINER, Noel. Uma análise da textura aberta da linguagem e sua aplicação ao direito. Dissertação (Mestrado em Filosofia) - Pontifícia Universidade Católica do Rio de Janeiro (PUC-RJ), Rio de Janeiro, 2001. p. 16.

${ }^{20}$ SILVA, Guilherme. Ghizoni. Wittgenstein, Hipótese e Uso: As análises do tempo e a pragmática da linguagem, no início da década de trinta. In: Cognitio-Estudos (PUC-SP. Online), v. 6, p. 139-146, 2009. p. 141. 
esse universo hipotético, o mesmo universo hipotético que serviu de projeção à ideia de Waismann de textura aberta da linguagem.

É inegável, portanto, que as teorias de Wittgenstein e Waismann estejam entrelaçadas de modo simbiótico. Resta saber agora, como o contributo prestado por esses dois autores alcança a esfera jurídica. Existe de fato uma textura aberta também no Direito? A resposta a esta indagação traz consigo o prenúncio das nuances que serão enfrentadas no próximo ponto. A partir de agora, a teoria jurídico-filosófica de Herbert Hart assume o caminhar deste trabalho.

\section{HART E A CONSTATAÇÃO DE UMA TEXTURA ABERTA NO DIREITO}

A normatividade que compõe o Direito se vale da linguagem como principal instrumento de confecção das normas jurídicas. Logo, se a linguagem possui uma potencial vagueza, também o Direito a possui. Neste sentido, a textura aberta que no campo jurídico se instaura não pode ser outra coisa senão fruto da ausência de previsibilidade sobre eventos futuros. $^{21}$

A afirmação de que o Direito possui uma textura aberta ganha formas proeminentes a partir da filosofia jurídica de Herbert Hart. Para esse professor da Universidade Oxford, a mesma indeterminação que afeta a linguagem estende-se também à esfera jurídica, uma vez que a origem e a interpretação das normas estão inegavelmente atreladas a diversos elementos linguísticos. Logo, "nada pode eliminar essa dualidade entre um núcleo de certeza e uma penumbra de dúvida quando procuramos acomodar situações particulares ao âmbito de normas gerais. Isso confere a todas as normas uma margem de vagueza ou textura aberta". ${ }^{22}$

No caminho que conduz Hart à verificação de uma textura aberta no Direito, um turbilhão de influências positivistas agrega-se a um racional caminhar. Sem sombra de dúvidas, o Círculo de Viena e todas aquelas alegações oriundas do denominado positivismo lógico influenciaram sobre-

\footnotetext{
${ }^{21}$ NAVARRO, Pablo. Tensiones conceptuales em el positivismo jurídico. In: Doxa, n. 24, 2001. p. 120.

${ }^{22}$ HART, H. L. A. O conceito de Direito. Pós-escrito editado por Penélope A. Bulloch e Joseph Raz. Trad. de A. Ribeiro Mendes. 2.ed. São Paulo: Martins Fontes, 2012. p. 158.
} 
maneira a teoria do professor de Oxford. O maior contributo por ele encontrado naquele espaço acadêmico mostra-se proveniente das alegações de Waismann; tanto é que a textura aberta da linguagem se abre de forma a alcançar também normas jurídicas.

De fato, as pretensões de Hart se voltavam à apresentação de um conceito de Direito livre de especulações metafisicas. A intenção era afastar do Direito qualquer traço de Direito natural que por ventura viesse a impregnar a esfera jurídica de grandes incertezas. Criar um sistema jurídico pautado em uma hermenêutica capaz de fazer da norma o único elemento de previsibilidade era o que ele queria naquele momento. Suas aspirações jurídico-filosóficas, como bem se sabe, acabariam por reiterar o que hoje se conhece por positivismo jurídico analítico ${ }^{23}$.

Hart tinha consciência de que nem todas as situações poderiam ser previsíveis. Sabia também que essa imprevisibilidade que assolava o Direito arremessaria todos aqueles casos lacunosos a uma zona de potencial vagueza normativa, evento que somente poderia ser fruto de uma textura aberta da linguagem. Nessas situações anômalas, na qual conceitos se dispersavam, o socorro teórico prestado por Waismann se fazia salutar. Assim, uma vez embebido por essa conceituação, tecia o professor inglês a seguinte afirmação:

Qualquer que seja a estratégia escolhida para a transmissão de padrões de comportamento, seja o precedente ou a legislação, esses padrões, por muito facilmente que funcionem na grande massa de casos comuns, se mostrarão imprecisos em algum ponto,

\footnotetext{
${ }^{23} \mathrm{O}$ positivismo jurídico analítico firma-se como corrente jurídica que pretende definir os contornos do direito através da análise de conceitos jurídicos que levem em consideração a dimensão da linguagem. Oriundo do final do século XVIII, tendo Bentham como precursor, proporá a redução formal da linguagem jurídica como meio de se alcançar uma visão geral da estrutura formal do direito que seja idêntica para todos os sistemas jurídicos existentes (AUSTIN, 2002). Austin e Hart são considerados pela doutrina importantes representantes do positivismo jurídico analítico, todavia, é Kelsen quem se destaca como marco teórico singular, dada a preocupação do filósofo austríaco em separar, de um lado, o conhecimento jurídico do direito e, de outro, o conhecimento não jurídico do direito. Para mais informações, ver: KELSEN, Hans. Teoria pura do Direito. Trad. João Baptista Machado. São Paulo. 8. ed. Martins Fontes. 2014.
} 
quando sua aplicação for posta em dúvida; terão o que se tem chamado de textura aberta. ${ }^{24}$

Da passagem acima transcrita, torna-se possível perceber que no contexto hartiano a expressão textura aberta do Direito está sendo utilizada para se referir à existência de situações concretas não reguladas pelo Direito, situações essas que abrem possibilidades para que casos sem respostas legais passem a ser regulamentados pelos aplicadores do Direito. Para Hart, a insuficiência da linguagem jurídica como consequência de seu caráter simbólico e da grande abstração das regras é que gera essa textura aberta, manifesta tanto em relação à lei como em relação ao precedente judicial. $\mathrm{O}$ fato de haver um limite intrínseco à linguagem no processo de construção de um sistema jurídico é que faz com que a interpretação do texto normativo se torne vulnerável às incertezas, deixando transparecer um enorme ceticismo com relação ao grau de precisão das normas frente à regulamentação de situações concretas.

Havia, pois, um problema de incerteza normativa diagnosticado pela impossibilidade de se rever todas as possíveis situações passíveis de regulamentação diante de condutas futuras e incertas, uma vez ser impossível uma total previsão de acontecimentos pelo legislador. No entendimento de Hart, não existia qualquer possibilidade de idealização de um ordenamento jurídico constituído por um número infinito de regras capazes de alcançar todas as situações que se mostrassem inéditas em nosso quotidiano e, por esse motivo, ao Direito revelava-se uma inevitável abertura. Sob esse prisma, manifesta-se o professor de Oxford da seguinte forma:

A textura aberta do direito significa que existem, de fato, áreas de comportamento nas quais muita coisa deve ser decidida por autoridades administrativas ou judiciais que busquem obter, em função das circunstâncias, um equilíbrio entre interesses conflitantes, cujo peso varia de caso para caso. ${ }^{25}$

\footnotetext{
${ }^{24}$ HART, H. L. A. O conceito de Direito. Pós-escrito editado por Penélope A. Bulloch e Joseph Raz. Trad. de A. Ribeiro Mendes. 2.ed. São Paulo: Martins Fontes, 2012. p. 166.

${ }^{25}$ Ibidem. p. 175.
} 
Como se pode ver, essa noção de textura aberta do Direito acaba envolvendo questões atinentes à indeterminabilidade do processo de comunicação das regras jurídicas, haja vista a área de conduta deixada em aberto pelo legislador. Desse modo, para Hart, todas as vezes que um caso inédito não encontrar plausível solução no Direito vigente, dada a vagueza das normas existentes, o julgador deverá aplicar seu poder discricionário de forma a suprir a indeterminação normativa:

(...) por textura aberta deve-se entender esta zona de penumbra ou de indeterminação da linguagem jurídica que gera nos juízes a necessidade de exercer poder de eleição de sentido (dos muitos possíveis) sem que a técnica jurídica proveja os meios suficientes e necessários para se reduzir a margem de apreciação. ${ }^{26}$

Partindo desse pressuposto, entender-se-á que o reflexo direto da textura aberta do Direito não pode ser outro senão permitir que o magistrado faça uso da discricionariedade judicial com o escopo de suprir as lacunas geradas pela vagueza de determinados conceitos linguístico-normativos. Isso, no entanto, abre uma imensa margem de incerteza ao Direito, dado o abalo causado à segurança jurídica, que se vê afetada pela possibilidade de uma aplicação retroativa e despótica do Direito.

É importante que se saiba que são várias as críticas a essa noção de textura aberta do Direito. Para muitos autores, essa constatação hartiana serviria tão somente como convidativo impulso às arbitrariedades judiciais, já que abriria margens a um julgamento extrajurídico. Acredita-se, no entanto, que vários desses ataques teoréticos sejam desprovidos de sentido, permanecendo como se estivessem flutuando no ar.

Considerada por alguns como um infeliz empréstimo extraído da filosofia, a textura aberta do Direito permanece ainda no centro de diversas divagações doutrinárias. Ao perpassar pelas vereadas que circunscrevem todas elas, escolheu-se aqui aquele caminho que permite enxergar, por meio da constatação de Waismann, um importante contributo ao Direito. Acredita-se que essa noção filosófica resgatada por Hart venha justamente reduzir essa discricionariedade, já que permite a atuação discricionária dos

${ }^{26}$ SGARBI, Adrian. Teoria do Direito: primeiras lições. Rio de Janeiro: Lumen Juris, 2007. p. 465. 
magistrados apenas na zona de penumbra, onde atua uma potencial vagueza linguística. Neste sentido, vale a pena trazer à baila o seguinte posicionamento adotado por Bueno:

(...) a textura aberta do direito é contrabalanceada por um poder discricionário limitado por normas jurídicas, capaz de reduzir o campo de indeterminabilidade presente nas normas jurídicas com base em padrões e regras jurídicas no momento de sua aplicação, sem com isso eliminar tal desejável campo de abertura. ${ }^{27}$

Logo, a função da textura aberta do Direito é delimitar esses espaços vazios onde se torna permitida a discricionariedade judicial. Sem este instrumento verificacionista, haveria uma intromissão invasiva do magistrado em áreas onde sequer existem lacunas legislativas, o que geraria uma real insegurança jurídica, que poderia causar um colapso no sistema jurídico. Desta forma, embora esse mecanismo aja em área de conduta deixada em aberto pelo legislador, o seguinte raciocínio ainda se mostra plausível:

A textura aberta do direito, ainda que se apresente como precursora da discricionariedade judicial, não pode se apresentar como motivo determinante para que se possa vislumbrar o ordenamento jurídico como um emaranhado de decisões desprovidas de qualquer juízo de valor e fundamentadas nas escolhas pessoais dos magistrados. As decisões proferidas pelo julgador são o próprio freio ao livre discernimento pessoal do aplicador do direito, que as vê como um padrão a ser seguido nas novas decisões a serem tomadas. ${ }^{28}$

\footnotetext{
${ }^{27}$ BUENO, Roberto. Hart e o positivismo jurídico: em torno à hermenêutica e a textura aberta da linguagem do Direito. In: Revista de Informação Legislativa, v. 47, p. 275-290, 2010. p. 288.

${ }^{28}$ BAHIA, Charles Nunes. A discricionariedade judicial à luz das teorias de Hart e Dworkin. In: Âmbito Jurídico, Rio Grande, XVI, n. 118, nov $2013 \mathrm{a}$.
} 
Prevalece aqui, portanto, a ideia de que a textura aberta da linguagem, quando aplicada ao Direito, atua como importante e singular instrumento capaz de não apenas captar o fenômeno da discricionariedade judicial, mas também de delimitar o espaço de atuação de um poder discricionário concedido aos juízes para atender à natural ausência de previsibilidade normativa em várias situações que inundam diariamente a esfera jurisdicional. Logo, se o problema não está resolvido, ao menos está bem diagnosticado.

\section{CONSIDERAÇÕES FINAIS}

As implicações filosóficas legadas por Wittgenstein e Waismann causaram uma profunda transformação na esfera jurídica. Pelas mãos de Hart, uma revolução acontecia no Direito: era o século XX prenunciando mudanças significativas em relação a paradigmas normativos. Naquele momento, a norma deixava de ser sinônimo de certeza e total previsibilidade para dar lugar a uma incerteza irremediável. Constatava-se um espaço lacunoso incapaz de ser preenchido de antemão; fazia-se notório o fato de que o Direito possuía uma textura aberta decorrente da textura aberta da linguagem. Posto isto, abria-se espaço à necessidade de que todas as situações desprovidas de regulamentação, consideradas aquelas marcadas por imprecisões linguísticas, fossem colmatadas por um poder discricionário exercido da forma mais equânime e racional.

A verdade é que Hart não se conformava com a ideia de que o Direito poderia regular absolutamente tudo; o dia-a-dia do judiciário evidenciava um cenário no qual vários casos se viam desprovidos de solução. Esse fenômeno, que muitas vezes desencadeava arbitrariedades judiciais, apresentava-se como uma incógnita diante do professor de Oxford. Algo estava errado, e as origens desse erro não pareciam estar fincadas nas teorias jurídicas em si; as razões proeminentes habitavam o vale das imprecisões da linguagem.

Ao abordar o fenômeno da linguagem, foi inevitável não recorrer à Wittgenstein. Para o filósofo austríaco, a linguagem, antes preocupada unicamente com sua figuração do mundo, se torna, num segundo momento, uma descrição de inúmeras atividades. Ela passa a se submeter a jogos, regras, compartilhando do que se tem chamado de semelhanças de família. Essa noção, no entanto, tão fragmentada na doutrina filosófica, não passa 
despercebida diante de críticas; nem mesmo esses metafóricos jogos pareciam conseguir suprir a imprecisão linguística causada pela linguagem. Nas palavras de Waismann, essa linguagem estaria impregnada por uma textura aberta.

Waismann segue, portanto, o caminho de Wittgenstein. Vai aprimorando conceitos, trabalhando significações, permanece irrequieto diante de uma potencial vagueza da linguagem. Desenvolve a noção de textura aberta da linguagem e acaba a emprestando à filosofia jurídica de Hart. A partir daí se torna claro que o motivo pelo qual as normas não conseguem muitas vezes alcançar determinados casos não legislados não pode ser outro senão a imprecisão linguístico-normativa, imprecisão esta que confirma a existência de uma textura aberta também no Direito.

\section{REFERÊNCIAS BIBLIOGRÁFICAS}

AUSTIN, John. The province of jurisprudence determined and the uses of the study of jurisprudence.[1832] London: Weindenfeld and Nicolson. Tradução de Juan Ramon de Páramo Argüelles, El objecto de la jurisprudencia. Madrid: CEC, 2002.

BAHIA, Charles Nunes. A discricionariedade judicial à luz das teorias de Hart e Dworkin. In: Âmbito Jurídico, Rio Grande, XVI, n. 118, nov 2013a.

. Positivismo Jurídico e Nazismo: a superação do mito. In: Âmbito Jurídico, Rio Grande, XVI, n. 116, set 2013b.

BUENO, Roberto. Hart e o positivismo jurídico: em torno à hermenêutica e a textura aberta da linguagem do Direito. In: Revista de Informação Legislativa, v. 47, p. 275-290, 2010.

CAVASSANE, Ricardo Peraça. A crítica de Wittgenstein ao seu Tractatus nas Investigações Filosóficas. In: Revista de Iniciação Científica da F.F.C., v 10, p. 3, 2010.

COLONTONIO, Carlos Ogawa. A questão da racionalidade jurídica em Hart e Dworkin. Dissertação (Mestrado em Filosofia) Universidade de São Paulo, São Paulo. 2011.

HART, H. L. A. O conceito de Direito. Pós-escrito editado por Penélope A. Bulloch e Joseph Raz. Trad. de A. Ribeiro Mendes. 2.ed. São Paulo: Martins Fontes, 2012. 
KELSEN, Hans. Teoria pura do Direito. Tradução de João Baptista Machado. $8^{a}$ ed. São Paulo: Martins Fontes, 2014.

NAVARRO, Pablo. Tensiones conceptuales em el positivismo jurídico. In: Doxa, n. 24, 2001.

SGARBI, Adrian. Teoria do Direito: primeiras lições. Rio de Janeiro: Lumen Juris, 2007.

SILVA, Guilherme. Ghizoni. Wittgenstein, Hipótese e Uso: As análises do tempo e a pragmática da linguagem, no início da década de trinta. In: Cognitio-Estudos (PUC-SP. Online), v. 6, p. 139-146, 2009.

STRUCHINER, Noel. Uma análise da textura aberta da linguagem e sua aplicação ao direito. Dissertação (Mestrado em Filosofia) Pontifícia Universidade Católica do Rio de Janeiro (PUC-RJ), Rio de Janeiro, 2001.

WAISMANN, Friedrich. Verifiability. In: FLEW, Antony (coord.). Logic and language. Oxford: Balckwell, 1978, p. 177-144.

WITTGENSTEIN, Ludwig. Investigações filosóficas. Tradução de M. S. Lourenço. Lisboa: Fundação Calouste Gulbenkian, 2002a.

. Tratado lógico-filosófico. Tradução de M. S. Lourenço. Lisboa: Fundação Calouste Gulbenkian, 2002b. 